\title{
SEGUNDA NOTÍCIA SOBRE UMA GEOGRAFIA DE PORTUGAL NOVA E MONUMENTAL
}

\author{
ILÍDIO DO AMARAL ${ }^{1}$
}

Em Finisterra - Revista Portuguesa de Geografia, 2006, XLI(81): 233-242, foi incluída a "Primeira Notícia", dedicada à parte de Geografia Urbana do segundo volume da Geografia de Portugal, obra sob a direcção geral de Carlos Alberto Medeiros e editada pelo Círculo de Leitores. Na Notícia que ora se publica as informações dizem respeito ao primeiro volume, $O$ Ambiente Físico, Julho/Agosto de 2005, e à parte inicial do segundo, Sociedade, Paisagens e Cidades, Dezembro do mesmo ano. O quadro I dá o encadeamento das matérias tratadas e os seus autores.

Quadro I - Resumos dos índices gerais dos volumes I e II (este sem a parte sobre Cidades) Table I - Summaries of the general indices of volumes I and II (this without the part on Cities)

Volume I - O Ambiente Físico (496 páginas, um pouco mais de duas centenas de figuras e número semelhante de fotos*, 21 quadros, bibliografias extensas**)

Apresentação e Um Preâmbulo Geral. Palavras Prévias (Carlos Alberto Medeiros), pp. 10-47.

O Ambiente Físico. Palavras Prévias (António de Brum Ferreira), pp. 50-51.

Parte I - Formas do relevo e dinâmica geomorfológica (António de Brum Ferreira), pp. 53-255. Introdução. Estruturação geológica do terreno. Geomorfologia do Maciço Antigo. Geomorfologia das Bacias Sedimentares. Geomorfologia vulcânica das ilhas. Formas de relevo e dinâmica quaternária: Dinâmica recente e actual (com duas contribuições, uma de Catarina Ramos, "A Dinâmica Fluvial", e outra de Maria Eugénia Moreira, "A Dinâmica dos Sistemas Litorais").

Parte II - O espaço Atlântico Oriental (Denise de Brum Ferreira), pp. 257-303. Introdução. A dinâmica do Oceano. Hidrologia e dinâmica do mar português. Ambiente oceânico e recursos biológicos.

Parte III - O ambiente climático (Denise de Brum Ferreira), pp. 305-385. Introdução. As condições genéticas do clima. As características do clima de Portugal. O clima de Portugal estará a mudar?

1 Geógrafo. Professor Catedrático Jubilado da Universidade de Lisboa. Colaborador do Centro de Estudos Geográficos de Lisboa. Membro da Academia das Ciências de Lisboa e da Academia Portuguesa da História. E-mail: idoamaral@hotmail.com 
Parte IV - Os recursos hídricos (Catarina Ramos), pp. 387-415.

Introdução. Enquadramento de Portugal no contexto euro-mediterrâneo.

Os recursos hídricos superficiais. Recursos hídricos subterrâneos. Recursos hídricos das Regiões autónomas.

Parte $V$ - A vegetação (Maria Eugénia Moreira e Carlos da Silva Neto), pp. 417-482

Introdução sobre a fitogeografia de Portugal. A vegetação natural.

A vegetação introduzida.

Coordenação do volume: António de Brum Ferreira.

Volume II - Sociedade, Paisagens e Cidades (419 páginas, 163 figuras, 247 fotos, 78 quadros, bibliografias extensas)

Introdução (Teresa Barata Salgueiro e João Ferrão), pp. 12-15.

Parte I - Evolução histórica e ocupação do território (Carlos Alberto Medeiros), pp. 17-47. Primórdios da evolução do País; a expansão marítima e os seus reflexos. Os novos desafios do século XIX; evolução demográfica até ao primeiro censo (1864).

Parte II - População e território (João Ferrão, Isabel Margarida André, Jorge Macaísta Malheiros, João Ferrão e Teresa Sá Marques, Teresa Pinto/Correia), pp. 49-173.

Dinâmicas demográficas: uma visão panorâmica. Família e género. Migrações. População, qualificações e capital cultural. Desenvolvimento humano e coesão social. Paisagem e identidade: da memória à pós-modernidade.

Coordenação do volume: Teresa Barata Salgueiro e João Ferrão.

* Em números aproximados porque algumas imagens têm numeração desdobrada com letras - A, B, ...

** As informações bibliográficas estão em letra menor que a dos textos; estes estão em duas colunas por página, aquelas em três colunas.

\section{O AMBIENTE FÍSICO OU NATURAL}

No início de "O Ambiente Físico", temática fundamental do Primeiro volume, o seu coordenador, António de Brum Ferreira, começou por recordar a distinção feita por Orlando Ribeiro, e tornada clássica, entre um Portugal mediterrânico e um Portugal atlântico (Portugal, o Mediterrâneo e o Atlântico, 1945, e várias reedições), e sublinhou quanto há de variedade e complexidade na área continental e nas ilhas, não só por virtude das diferenças climáticas mas também pela presença de outros factores igualmente importantes e variados, como os materiais rochosos e as suas estruturas, fundações básicas de qualquer território. Os efeitos do clima, porém, incluídas as suas variações temporais e espaciais, têm uma presença constante e visível sobre as paisagens naturais, os processos e evolução das formas de relevo, as condições hidrológicas, as coberturas pedológica e vegetal, e, enfim, a presença efectiva do homem (e todo o resto zoogeográfico) e as suas actividades.

Desde logo os leitores menos informados são avisados do "desigual desenvolvimento de cada uma das partes" do volume, o "que traduz, de certo modo, a evolução díspar da geografia física no nosso país", mais acentuada e ampla em domínios como da geomorfologia e da climatologia, menos os da hidrologia e da fitogeografia, aliás como sucede em muitos outros países. Acrescento eu que nada há de extraordinário no "desigual desenvolvimento", tendo em conta que se trata de uma obra de vários autores, cada um deles com a sua personalidade e os seus interesses em domínios tratados, e os progressos desiguais dos conhecimentos no quadro das especializações de disciplinas afins da Geografia 
no decorrer do século passado. Mas isso não os impediu de verem o global (que a especialização fragmenta em parcelas), bem como o essencial (que ela dissolve). Os problemas essenciais não são jamais parcelares, e os globais são cada vez mais essenciais. Nisto está a virtude desta Geografia de Portugal, da coordenação das várias partes dos seus volumes - repito que, por agora, apenas li atentamente os dois primeiros; o terceiro e o quarto percorri-os por alto - no sentido da garantia de uma harmonia geral.

Em boa hora o Atlântico próximo recebeu a devida atenção, pois desde há muito o oceano deixou "de ser uma mancha azul nos mapas, para se transformar cada vez mais num espaço geográfico, objecto de estudos fundamentais para a compreensão do funcionamento do planeta e, mesmo, para a sobrevivência da humanidade". A propósito disto ocorre recordar a cerimónia oficial que teve lugar em Lisboa, com representações de chefes de Estado e de Governo de vários países, e de muitas outras personalidades importantes, nacionais e estrangeiras, para a apresentação do livro Para uma governação do Oceano no século XXI: Democracia, equidade e paz no Oceano. Declaração de Lisboa, 1998, da Comissão Mundial Independente sobre os Oceanos. Assinalo apenas algumas das ideias fundamentais aí contidas. "A nova perspectiva sobre o Oceano, que inspira esta Declaração, combina cinco elementos": unidade (necessidade de abandonar a imagem tradicional do Oceano como dividido em vários oceanos separados e distintos); urgência (lembrando a gravidade dos desafios manifestados em resultado da utilização actual do Oceano); potencialidade (referida ao extraordinário tesouro que, se bem cuidado e utilizado de forma criativa, o Oceano representa para os povos do mundo); oportunidade (possibilidades que oferecem uma nova ordem mundial e a crescente consciencialização da importância do Oceano para a sobrevivência da humanidade); e tutela (empenhamento activo dos cidadãos e da sociedade em geral no "estado de saúde" do Oceano).

O título da primeira parte do volume, "Formas do relevo e dinâmica geomorfológica", de que o coordenador é autor, marca as tonalidades dominantes de todas as contribuições: o forte dinamismo dos fenómenos geográficos; nada é fixo e imutável na superfície terrestre; pelo contrário, esta deve ser tomada como equiparável a um "corpo vivo" em evolução que varia no tempo e no espaço. Sirva de exemplo o que se passa com o substrato geológico. Se, à escala humana, o Maciço Antigo e as suas Orlas Sedimentares (só na parte continental) podem ser tidos como relativamente invariantes, apenas perturbados, de quando em quando, por uma ou outra falha activa, já os maciços vulcânicos e os sismos (predominantes nas ilhas açorianas) traduzem, de forma clara, a instabilidade da crosta, os movimentos migratórios das suas placas. E de modo idêntico se pode dizer de outras alterações bem visíveis, como as do clima, da hidrologia, da vegetação, para as quais muito contribuem as intromissões humanas, sobretudo as que perturbam o equilíbrio sensível entre a sua presença e a natureza.

"Falar de geografia é falar do território, e o território é, antes de mais, a terra que a gente pisa", são palavras na abertura da "Introdução", a que se seguem os capítulos dedicados à "Estruturação geológica do território", à "Geomorfologia do Maciço Antigo", à "Geomorfologia das Bacias Sedimentares", à "Geomorfologia vulcânica das ilhas", às "Formas de relevo e dinâmica quaternária", e à "Dinâmica recente e actual". Tomando em conta elementos meramente estatísticos, logo se vê que, do total de cerca de 180 páginas, os dois últimos capítulos detêm um pouco mais da metade, o que de certo modo se compreende, tendo em conta os progressos recentes dos estudos sobre os processos e as formas do Quaternário ao Actual, as preocupações de determinação, previsão e monitorização de riscos de origens natural e antrópica, com implicações importantes nos modelos de ordenamento do território. 
O autor desta primeira parte começou-a pela "Estrutura geológica do território", dando-lhe um desenvolvimento clássico: depois de uma Introdução com um breve quadro da história geológica da Terra, demorou-se sobre a estrutura do Maciço Hespérico, o soco antigo do Precâmbrico ao Fanerozóico, o Paleozóico e o orógeno varisco, o Mezozóico e a abertura do Atlântico, a sedimentação cenozóica, a tectogénese alpina e o relevo da Península Ibérica.

Na sequência, o segundo capítulo foi preenchido com a "Geomorfologia do Maciço Antigo" português, extremidade ocidental do Maciço Hespérico, uma das unidades morfoestruturais a que se associam extensas superfícies de aplanação com os seus relevos residuais, alguns deles de origem tectónica. Dadas as grandes áreas de afloramentos de rochas graníticas e xistentas, atenção especial mereceram as características particulares dos seus modelados, seguindo-se sínteses do relevo regional, do Norte da Beira, de Trás-os-Montes e Minho, de Portugal central, do Alentejo, faltando apenas, a meu ver, o do Algarve, ainda que no capítulo seguinte fosse incluída a parte do Barrocal.

No terceiro capítulo, "Geomorfologia das Bacias Sedimentares", o autor preferiu tratar em conjunto "a caracterização geomorfológica das Orlas Sedimentares mesocenozóicas do Maciço Antigo e também da bacia sedimentar cenozóica do Tejo-Sado", começando pelo exemplo dos relevos de costeiras a norte de Lisboa, de Loures e Bucelas, e depois os modelados em estruturas enrugadas e falhadas, citados os casos já clássicos da serra da Arrábida e do Maciço Calcário Estremenho, e ainda os do Maciço de Sicó e do Barrocal algarvio. Predominando rochas calcárias, associadas a outras de grande elasticidade, nomeadamente argilosas, não podia deixar de haver, por um lado, notícia sobre os vales diapíricos e, por outro, sobre as formas cársicas, de que Portugal tem um rico mostruário em várias partes da sua Orla Sedimentar, sobretudo no Maciço Calcário Estremenho. O capítulo termina com o relevo da bacia sedimentar Tejo-Sado, "a unidade morfoestrutural mais recente do País, e, por isso mesmo, a menos afectada pelas deformações tectónicas", aproximadas "pelas características geomorfológicas, e, até, geográficas".

No capítulo seguinte, dedicado às ilhas e à sua "Geomorfologia vulcânica", depois de uma "Introdução" as alíneas são as seguintes: tectónica e vulcanismo dos Açores, etapas da estruturação das ilhas açoreanas, geomorfologia das ilhas, com amplas notas sobre cada uma delas, e depois, de forma idêntica, Madeira e Porto Santo. O vulcanismo volta a ser abordado em capítulo sobre "Dinâmica actual e recente".

Note-se que, até aqui, predominou a apresentação de formas de relevo intimamente ligadas às estruturas geológicas, que a erosão, tomada no seu sentido mais amplo, decalcou. No seguimento vêm, pelo contrário, as que têm sido predominantemente cinzeladas pelos complexos processos erosivos, ligados não só à variabilidade das condições climáticas e dos cobertos vegetais mas também às actividades antrópicas. Assim, no quinto capítulo, "Formas de relevo e dinâmica quaternária", depois de uma pequena introdução sobre a originalidade do Quaternário na história da Terra, foram sintetizadas as suas características gerais em Portugal, cujo território "esteve sujeito a um regime tectónico de levantamento, o que significa que, nele, nos últimos dois milhões de anos, a erosão predominou largamente sobre a sedimentação". Não obstante, o autor começou pelos depósitos, a partir das rañas, procurando apresentá-las de maneira "mais sistematizada, de modo a tentar definir o significado paleogeográfico [...] e ver em que medida eles podem constituir uma referência estratigráfica de separação entre o Neogénico (fim do Terciário) e o Quaternário". Num esquema já clássico, vêm de seguida os terraços e a organização dos sistemas fluviais (aspectos teóricos sobre a origem dos ter- 
raços, sua existência e características em Portugal, organização geral da drenagem), a plataforma litoral e as praias quaternárias (sempre do geral para Portugal), o seu escalonamento, e efeitos da transgressão flandriana.

O Quaternário foi marcado por oscilações do nível dos oceanos, relacionadas com o ritmo de glaciações. Portugal, pela sua posição geográfica e pelo facto de não ter maciços orográficos de grande altitude, como sucede nos Alpes e congéneres - no continente, a serra da Estrela tem apenas $1991 \mathrm{~m}$ de altitude, que é ultrapassada pela do Pico (ilha do mesmo nome), com 2 345m -, não teve calotes glaciárias nem glaciares maciços e extensos. No entanto, não deixa de haver importantes manifestações da dinâmica glaciária e crionival (arrefecimento plistocénico), cujas formas de relevo e depósitos têm merecido estudos recentes de pormenor.

O capítulo sexto, "Dinâmica recente e actual", teve como abertura os fenómenos vulcânicos, natureza e ritmo das erupções, vulcões activos e potencialmente activos. Foram escolhidos abundantes exemplos açoreanos, referidas as erupções desde meados do século XVI, registadas em documentos dos primeiros tempos da ocupação das ilhas, até à erupção submarina da Serreta, ao largo da Terceira, em 1998/2001. O seguimento foi dado aos fenómenos sísmicos, com algumas informações sobre a sismicidade no continente e a fronteira das placas tectónicas Açores-Gibraltar, a sismicidade e sismotectónica no continente (sem esquecer o célebre terramoto de 1755) e nos Açores, sendo as da Madeira e Porto Santo quase irrelevantes, e terminou com breve nota sobre o sismo de Julho de 1998 que afectou sobretudo uma parte do Faial, São Jorge e Pico. O quadro de alterações e movimentos sensíveis e por vezes destrutivos da superfície terrestre não ficaria completo sem a abordagem de fenómenos tão importantes como os de perigosidade geomorfológica: movimentos resultantes da instabilidade de vertentes fluviais e arribas litorais (quedas de materiais por gravidade, deslizamentos e escoadas), os efeitos da erosão hídrica dos solos (ravinamentos) e daquelas promovidas pelos incêndios e pelas actividades humanas, com exemplos regionais e locais de perturbação do equilíbrio ecológico. O mais grave está em que contribuem para o aumento da desertificação de áreas rurais, no sentido duplo do termo: erosão dos solos e êxodo populacional.

Catarina Ramos contribuiu com uma parte sobre a dinâmica fluvial (os rios como agentes modeladores, as lezírias do Tejo, a influência das barragens) e Maria Eugénia Moreira sobre a dinâmica dos sistemas litorais (geossistemas de arriba, de praia e dunares, fluviomarinhos - estuários e deltas, os de costa lagunar) e o impacte das catástrofes naturais, relacionadas com fenómenos climáticos (tempestades), sísmicos, artificiais (marés negras, pelos derramamentos de crude) e de ocupação humana.

Coube a Denise de Brum Ferreira a responsabilidade da segunda e da terceira partes, "O espaço atlântico oriental" e "O ambiente climático". Relativamente à primeira, a autora teve razão em recordar, na Introdução, que "a geografia e o passado histórico de Portugal estão intimamente ligados ao oceano", que "pela sua posição de finisterra, na fachada ocidental da Península Ibérica, o território nacional contacta directamente com o Atlântico Norte ao longo de cerca de $850 \mathrm{~km}$ de costa" e que, "projectado sobre os arquipélagos dos Açores e da Madeira, o mar português avança numa distância de mais de $2000 \mathrm{~km}$, para oeste, e de $1000 \mathrm{~km}$, para sul". Assim, "território de dimensão reduzida, Portugal possui, no entanto, a maior Zona Económica Exclusiva (ZEE) da União Europeia, com cerca de 1,7 milhões de quilómetros quadrados, ou seja, uma área dezoito vezes superior à sua extensão terrestre".

O facto de não ter sido usual, em obras anteriores de Geografia de Portugal, a apresentação aprofundada, dinâmica e actualizada de dados sobre o oceano, cuja impor- 
tância ficou bem assinalada, leva-me a demorar sobre esta parte do volume. Depois da Introdução, com algumas notas sobre a evolução dos estudos oceanográficos e os meios utilizados, até aos conhecimentos mais actuais conseguidos pela interpretação de dados recolhidos por sensores de tecnologia sofisticada transportados em satélites de vários tipos e trabalhados em agências que os controlam, abrem-se três capítulos - "A dinâmica do Oceano", "Hidrologia e dinâmica do mar português", e "Ambiente oceânico e recursos biológicos", mais duas páginas e meia de bibliografia, em que as matérias são apresentadas com rigor científico, mas em que se nota, como sucede em todo o volume, a preocupação de uma escrita clara de modo a tornar-se inteligível, quer para aqueles leitores que não sejam especialistas, quer para os que estejam menos informados e actualizados.

Assim, no primeiro capítulo a autora preocupou-se com as propriedades da água oceânica (consequências da salinidade, identificação das massas de água e os contactos entre elas), os processos que definem as propriedades e dinâmica dos oceanos (controlos da salinidade e da temperatura - aspectos do balanço energético oceano-atmosfera, sobretudo no Atlântico Norte) e os que geram o movimento da água (giros e turbilhões, circulações costeiras).

No segundo capítulo, sobre a "Hidrologia e dinâmica do mar português", mantendo a originalidade do anterior, foram relevadas as características topográficas dos fundos submarinos do mar português (a dorsal médio-atlântica, as planícies abissais, os montes submarinos, a margem continental), a renovação das ideias sobre a hidrologia regional, a corrente dos Açores (suas características gerais e origem), a água modal madeirense, o sistema de correntes ao longo da costa portuguesa (regimes de Inverno e de Verão das correntes da margem oriental, upwelling durante o Verão e circulação das águas costeiras no Algarve durante a mesma estação, a entrada de água do Mediterrâneo no Atlântico) e uma conclusão sobre a originalidade da dinâmica da bacia do Atlântico oriental, sublinhando-se que "os fenómenos hidrológicos que nascem e evoluem no Atlântico oriental entre a Península Ibérica, os Açores e a Madeira não resultam da corrente do Golfo", pois "a chave da interpretação da circulação e da hidrologia das camadas superiores do Atlântico subtropical oriental é a corrente dos Açores, que acompanha uma frente de dinâmica complexa separando dois tipos de água de densidade diferente".

O terceiro capítulo, "Ambiente oceânico e recursos biológicos", constitui uma espécie de guia de aplicação do aprofundamento dos conhecimentos oceanográficos, um alerta a cuidados que exigem a exploração e a conservação dos recursos biológicos, assunto da maior importância, em face das consequências negativas da exploração desregrada dos recursos terrestres. Chave mestra do pensamento científico da autora foi sublinhada na "interacções entre a água oceânica e a atmosfera suprajacente ou da própria dinâmica do oceano", com importantes influências "na produção de biomassa fitoplanctónica, base da diversidade e abundância da vida marinha, e, em última análise, na valorização da ZEE para a actividade piscatória". O capítulo inclui a organização da vida no oceano, a zonagem dos ambientes marinhos, os avanços do conhecimento devido à teledetecção por satélites, as tentativas recentes de delimitação dos ecossistemas marinhos (propostas de vários investigadores), biomassa planctónica e produtividade primária no mar português (produção de fitoplâncton e ritmo sazonal, produtividade total média anual, reforços locais de produtividade no mar alto - o papel dos ecótomos), recursos piscatórios e dinâmica do ambiente oceânico na ZEE nacional (declínio das capturas de pequenos pelágicos e a dinâmica do ecossistema costeiro oriental, migração dos tunídeos). 
Tal como mencionei anteriormente, Denise de Brum Ferreira também teve a responsabilidade da terceira parte do volume, "O Ambiente climático". No início da Introdução defendeu que "no estudo do ambiente físico, a dinâmica da atmosfera e o clima são factores importantes a considerar, porque têm uma influência determinante sobre as características das paisagens, sobre os modos de vida, a saúde e o bem-estar das populações, e imprimem a sua marca em vários ramos da actividade económica, criando potencialidades, introduzindo factores limitantes, limiares de tolerância, necessidades de adaptação". Em notas breves apresentou dados sobre a evolução dos estudos de clima na Península Ibérica e em Portugal, a rede de pontos de observação, a utilização de satélites, antes da abordagem das matérias contidas em três capítulos: "As condições genéticas do clima", "As características do clima de Portugal" e "O clima de Portugal estará a mudar?", e ainda três páginas e meia de bibliografia.

No primeiro capítulo, os "principais factores que permitem elaborar uma diferenciação climática" começaram a ser apresentados à escala planetária (posição em latitude e ritmo da radiação solar, posição do território português na circulação atmosférica geral - o estudo dos elementos desta circulação através do METEOSAT e a originalidade da posição do espaço português -, modalidades da circulação de Oeste circulação zonal rápida, modalidades de escoamento do ar em circulação meridiana), importância dos tipos de circulação em altitude para o tempo e o clima de Portugal continental e das ilhas; depois à escala regional (Portugal continental na fachada ocidental da Península Ibérica - posição e dimensão, aberto a todas as massas de ar, e marcas da continentalidade, a proximidade do continente africano, a atmosfera marítima - marcas da oceanidade, ambientes climáticos insulares e estratificação vertical do ar); e ainda à escala local (efeito das massas de relevo - distribuição delas, efeitos mecânicos sobre o escoamento das massas de ar) e no caso da escala local não foi esquecido o efeito antrópico, com o exemplo do que sucede em áreas urbanizadas, nomeadamente a deterioração climática na região de Lisboa.

O segundo capítulo, "As características do clima de Portugal”, cujo conhecimento "é fundamental para se perceber as suas paisagens, o quadro de vida dos seus habitantes, antes de se proceder a qualquer tentativa de ordenamento e de uso sustentado do território", foi desenvolvido através de: a radiação solar e a insolação (distribuição da primeira e características da segunda no continente e nas ilhas), os contrastes térmicos (o ambiente invernal e os ambientes térmicos estivais, variedade dos regimes térmicos, extremos térmicos no Inverno e no Verão e situações meteorológicas associadas), distribuição e ritmo das chuvas em Portugal continental, nos Açores e na Madeira (repartição espacial média anual e os regimes pluviométricos), extremos diários das precipitações, os sistemas chuvosos e a variabilidade interanual do regime pluviométrico (grandes depressões migradoras de escala sinóptica, depressões do Atlântico subtropical oriental, actividade pluviosa das correntes perturbadas, tempestades ciclónicas, depressões nascidas entre os Açores e as Canárias, e ciclones tropicais do final do Verão e do Outono nos Açores), a aridez e as secas (definições, regionalização da aridez em Portugal continental e identificação das secas, as secas nas ilhas), as regiões climáticas do território continental (fundamentos da divisão em regiões, climas regionais), zonagem climática das ilhas.

No último capítulo, posto na interrogativa, "O clima de Portugal estará a mudar?", foram examinadas as causas globais externas e as internas, e as ligadas com actividades humanas (perigosidade das emissões de $\mathrm{CO}_{2}$ e outros gases para a atmosfera; Quioto e os problemas políticos, etc.) relacionadas com a "variabilidade interanual do clima 
com vagas de calor e de frio, secas ou, pelo contrário, com episódios de chuvas muito abundantes". Contidos no capítulo ficaram a modelização do sistema climático e a previsão da sua evolução, a dimensão da evolução do clima no século XX a partir dos factos de observação (evolução da temperatura e do regime pluviométrico), os mecanismos da variabilidade do clima na bacia do Atlântico Norte e na Península Ibérica (o primeiro modo de variabilidade do clima mundial: ENSO/LNSO - El Niño-Southern Oscilation/La Niña-Southern Oscilation - e o primeiro modo de variabilidade do clima no Atlântico Norte: NAO - North Atlantic Oscilation, consequências desta durante as suas fases positivas e as suas fases negativas, o seu ritmo), a previsão da evolução do clima de Portugal no horizonte de 2010 (ordem de grandeza da mudança de temperatura no século XXI e da quantidade e regime da chuva, as incertezas da previsão e as surpresas das retroacções no sistema climático do Atlântico Norte). O nascimento de uma nova "Idade do gelo", talvez antes do final deste século, é uma hipótese que está longe de ser descabida e que tem merecido a atenção de muitos especialistas, juntando o que se sabe do passado (acerca dos paleoclimas) e ao muito que se tem colhido no presente graças aos avanços tecnológicos, nomeadamente das nanotecnologias, que permitem "mergulhar" mais e mais profundamente no cada vez mais pequeno.

Num País ameaçado pela aridez e secas, em cuja parte continental as bacias superiores dos principais rios (Minho, Douro, Tejo, Guadiana) são partilhadas com a vizinha Espanha, "qualquer política de gestão de recursos hídricos deve assentar no conhecimento da distribuição espacial e temporal do recurso água", foi a frase do Plano Nacional da Água, 2001, que Catarina Ramos escolheu para abertura da Introdução da parte da sua autoria, "Os recursos hídricos" (pp. 386-414 e cerca de meia página de bibliografia). O desenvolvimento, depois de algumas breves notas de interesse sobre as políticas de gestão da água, de formação de recursos humanos, sobre a necessidade de modificação de hábitos consumistas, a elaboração de planos nacionais e regionais, e de acordos com a Espanha, ocupou quatro capítulos: "Enquadramento de Portugal no contexto euro-mediterrâneo" (a importância do balanço hídrico na avaliação das potencialidades hídricas naturais, o contraste Norte-Sul - 'países excedentários' e 'países deficitários' em água, o escoamento interno e externo - a dependência de Espanha, e as regiões hidrográficas portuguesas). "Os recursos hídricos superficiais" (o regime dos rios - escoamento superficial e produtividade das bacias hidrográficas, irregularidade, variações estacionais, estiagem, cheias, e diferenciação regional do regime dos rios, barragens e albufeiras - sua importância estratégica) e "Recursos hídricos subterrâneos" (as águas subterrâneas e sua dependência do subsolo, repartição geográfica dos sistemas aquíferos, avaliação das reservas hídricas subterrâneas e dos recursos hídricos renováveis, utilização das águas subterrâneas e sua vulnerabilidade e contaminação). "Recursos hídricos das Regiões Autónomas" (os arquipélagos da Madeira e dos Açores).

A última parte, "A vegetação" (pp. 416-480 e mais cerca de página e meia de bibliografia), com as assinaturas de Maria Eugénia Moreira e Carlos da Silva Neto, relevou o valor considerável do património florístico do continente e das regiões insulares, atribuíveis a várias causas (posição geográfica, mudanças climáticas do Quaternário, barreiras montanhosas, perenidade de hábitos culturais, etc.). A uma "Introdução sobre a fitogeografia de Portugal", seguem-se "A vegetação natural" (florestas caducifólias do Norte e Centro - carvalhais e vidoais, florestas marcescentes do Centro e do Sul cercais da Estremadura, da serra da Arrábida e do Algarve, florestas perenifólias do Sul - sobreirais, azinhais e montados de azinho, zambujais, florestas e formações ripícolas - amiais, freixiais, salgueirais, choupais e ulmeirais, tamargais, e loendrais, florestas 
de coníferas - pinhais, laurissilva insular da Madeira e dos Açores, formações arbustivas - matos; formações vegetais do litoral; disposição em altitude da vegetação das montanhas continentais e insulares). Em "A vegetação introduzida" foram incluídas as espécies alimentares, as industriais, as silvícolas, as medicinais e as ornamentais. A quinta parte terminou com um vasto e valioso elenco florístico, dados os nomes científico e vulgar, de A a Z (pp. 474-480, duas colunas por página).

\section{SOCIEDADE E PAISAGENS}

Quanto ao conteúdo do Segundo volume da Geografia de Portugal o leitor desta Notícia poderá começar por refrescar a memória voltando ao quadro I com os títulos das suas partes e os nomes dos respectivos autores. Não se incluiu o que se refere às cidades, por motivos recordados logo no início desta Notícia. Na "Introdução", os coordenadores, Teresa Barata Salgueiro e João Ferrão, listaram o "turbilhão de mudanças" dos últimos anos, "privilegiando a transformação nas paisagens", designadamente nas cidades, "em articulação com as alterações sociodemográficas", sem deixarem de ter em conta a perspectiva histórica que "ajuda a situar o presente". Isto faz-nos recordar o que Edgar Morin escreveu, em Os sete saberes necessários à educação do futuro (1999), quanto ao facto de ser necessário aos cidadãos do novo milenário, para que possam pensar os problemas do seu tempo, compreender, simultaneamente, a condição humana no mundo e a condição do mundo humano que, no decurso da história moderna, se tornou no da era planetária. Se desde o século XVI se entrou no processo continuado da "mundialização", esta ganhou maior amplidão e aprofundamento no século XX, evidenciada a emergência de um objecto novo, o mundo como tal. Segundo o mesmo autor, "o planeta não é um sistema global, mas um turbilhão em movimento".

Para se ter uma ideia do turbilhão de mudanças à escala global os coordenadores do volume citaram algumas e para o caso português distinguiram as seguintes, aqui reproduzidas com ligeiras modificações: "alteração geoestratégica, com o encerramento do ciclo do império colonial e a adesão à União Europeia"; novo sentido da "posição euro-atlântica" e centralidade no Oceano; "redução muito significativa da agricultura e da indústria, com a transição para uma economia baseada nos serviços"; "modernização das infra-estruturas básicas de mobilidade e saneamento, menos conseguida" em alguns sectores (equipamentos, educação, saúde e protecção social) por força do atraso da "construção social do Estado-providência e ainda mais débil quando emergem as tendências para o seu desmantelamento e privatização dos respectivos serviços; envelhecimento demográfico e inversão do sentido das tendências migratórias dos últimos séculos"; "o regresso à sociedade pluriétnica, que noutras épocas caracterizou o País; e o "abandono progressivo de muitas regiões do interior e o aumento da concentração urbana no litoral, crescimento do nível de vida e dos níveis de consumo, designadamente com a expansão muito rápida da taxa de motorização das famílias e da posse de segunda habitação".

No desenvolvimento das partes e seus capítulos foram referidos outros factores de mudanças. Tratando-se de matérias do domínio da Geografia em que a diversidade humana, cultural, social, económica e política, e a sua variação no tempo e no espaço têm papéis de relevo, não admira que "mudança" seja a palavra-chave em todas as contribuições. De resto, também no primeiro volume, preferida a palavra "dinâmica", o sentido foi praticamente o mesmo. Comparando os dois volumes, notam-se algumas diferenças: no segundo, as regiões autónomas da Madeira e dos Açores, ainda que encar- 
tadas na maioria dos mapas de Portugal com índices, indicadores, etc., não foram apresentadas em textos separados; nessas figuras, dada a escala utilizada, à policromia continental, representativa da variabilidade dos aspectos tratados, correspondeu a monocromia insular; mesmo no capítulo sobre paisagem e identidade não se juntou um único documento fotográfico para mostrar a (enorme) diversidade de paisagens insulares; são raras as listas bibliográficas no fim de capítulos.

A primeira parte do segundo volume, "Evolução histórica e ocupação do território" (pp. 16-45 e um pouco mais de uma página de bibliografia) contém dois capítulos, ambos da autoria de Carlos Alberto Medeiros, o primeiro sobre os primórdios da evolução de Portugal, a expansão marítima e os seus reflexos, com a preocupação de sublinhar "alguns aspectos da evolução histórica do país que interferem com a compreensão da sua geografia humana"; e o segundo sobre os novos desafios do século XIX, sobretudo depois da independência do Brasil, a coroa de glória do espaço ultramarino, e a evolução demográfica até ao primeiro recenseamento (1864), "elemento importante de uma conjuntura nacional" caracterizada por mudanças importantes. De uma forma sóbria o autor traçou os quadros da situação quase marasmática de uma "monarquia agrária" medieval num país pouco povoado e periférico, para o do turbilhão da viragem para o exterior no século XV, isto é, dessa saga das descobertas e exploração de mundos novos que tanto revolucionaram o conhecimento medievo da Terra, iniciando o roteiro pelas experiências e sequências da ocupação humana de ilhas despovoadas, nos arquipélagos da Madeira, dos Açores e depois de Cabo Verde, os contactos com povos e culturas da costa de África, a passagem do Atlântico para o Índico e o encontro da Índia fabulosa e de outras terras, a travessia do Atlântico Sul e o Brasil até então de todo desconhecido pelos europeus.

Encerram o primeiro capítulo algumas notas sobre os séculos XVII e XVIII, acerca das interferências da Inglaterra (referências ao Tratado de Methuen e ao desenvolvimento da cultura da vinha no Alto Douro) e do Brasil ainda como elemento basilar do império português. Tendo sido referidos dois acontecimentos importantes do tempo do Marquês de Pombal, pena é que não se juntasse o relativo às reformas educativas, como as do ensino superior, e culturais por ele promovidas. No segundo capítulo foram tratados os factos significativos do século XIX e as interpretações divergentes, e sobretudo a evolução demográfica, concluindo com duas notas breves sobre a evolução recente, até à entrada de Portugal na CEE, depois do 25 de Abril de 1974, e a integração na União Europeia.

"População e território" é o título da segunda parte, em que colaboraram João Ferrão, Isabel Margarida André, Jorge Macaísta Malheiros, Teresa Sá Marques e Teresa Pinto Correia. Em vista da dimensão, variedade e número de autores, julgo benéficas as referências do quadro II.

Quadro II - Capítulos e autores de parte do volume II Table II - Chapters and authors of the second part of volume II

\begin{tabular}{llr}
\hline \multicolumn{1}{c}{ Capítulos } & \multicolumn{1}{c}{ Autores } & Pág. \\
1. Dinâmicas demográficas: uma visão panorâmica & João Ferrão & $50-71$ \\
2. Família e género & Isabel M. André & $72-86$ \\
3. Migrações & Jorge M. Malheiros & $87-124$ \\
4. População, qualificações e capital cultural & J. Ferrão e T. Sá Marques & $126-140$ \\
5. Desenvolvimento humano e coesão social & Isabel M. André & $141-150$ \\
6. Paisagem e identidade: da memória à pós-modernidade & Teresa Pinto Correia & $151-167$ \\
\hline
\end{tabular}


João Ferrão, depois de uma "Introdução", arrumou as matérias por temas, alguns dos quais em forma de desafios, como a evolução temporal das dinâmicas: a dupla convergência, subdividida em três fases (finais do século XIX/anos 50 do século XX, o arranque tardio da transição demográfica; início dos anos 60/começo dos anos 90, a concretização tardia do processo de modernização demográfica; e meados dos anos 90actualidade, a caminho de um modelo demográfico europeu comum?) e o assunto continua com futuro (meados do século XXI), por fim, um membro incontestado do clube de modelo demográfico europeu comum? Passando à evolução espacial das dinâmicas demográficas, o reforço das assimetrias territoriais, definiu a transição como um processo a várias velocidades..., debruçou-se sobre as espacialidades da mudança demográfica, reconfigurações e assimetrias, para terminar com modernização demográfica, uma leitura de síntese.

Muito ligado a este primeiro capítulo está o quarto, "População, qualificações e capital cultural", assinado por João Ferrão e Teresa Sá Marques. Em cerca de catorze páginas, com vários mapas, fotos e quadros de grande dimensão, a população em geral foi apresentada em estádio de qualificação acelerada mas insuficiente, examinadas características da população activa (desemprego, feminização, envelhecimento), do que chamam "bacias de emprego" (duas metrópoles, Lisboa e Porto, a primeira, com um raio de influência nacional, mais madura que a segunda, e diversas cidades médias; sistemas policêntricos ou lineares de âmbito sub-regional; pequenos centros com um raio de influência de proximidade; e municípios caracterizados pela ausência de fluxos intermunicipais significativos, e mobilidade geográfica como condição de acesso ao mundo do trabalho - êxodo rural, movimentos pendulares, mobilidades cruzadas, etc.), os territórios como contextos de qualificação e capacitação humana, e Portugal, um longo caminho por percorrer.

O quadro geral do país é nitidamente desolador. Duas frases, uma do início e outra do fim do capítulo, que dizem praticamente o mesmo, exprimem o que quero dizer: "apesar das melhorias observadas nas últimas décadas, nomeadamente como consequência do alargamento do período de escolaridade obrigatória e da democratização do acesso ao ensino superior, a população portuguesa continua a deter baixos níveis de instrução e qualificação por comparação com os países mais desenvolvidos"; e "apesar das melhorias indiscutivelmente observadas nas últimas décadas, a sociedade portuguesa continua a deter baixos índices de qualificações e de capacitação humana, ou seja, de capital cultural, no contexto europeu".

Embora me considere um optimista convicto, não posso deixar de definir a situação como preocupante, em face da célebre "Estratégia de Lisboa", documento longo e minucioso gizado quando Portugal teve a Presidência da União Europeia e o apresentou em reunião magna de Lisboa, em 2000. Os 15 membros de então assumiram fazer da União, até 2010, "a economia baseada no conhecimento" (o itálico é da minha responsabilidade) "mais dinâmica e competitiva do mundo, capaz de garantir um crescimento económico sustentável, com mais e melhores empregos e com maior coesão social". Constituiu um projecto demasiado ambicioso, perante os imensos desafios que já se anunciavam e o tempo confirmou e ampliou: alargamento da União a países de fraco desenvolvimento e carecidos de importantes alterações económicas e sociais (a maior parte deles saídos de regime comunista), fraqueza de crescimento económico mesmo nos mais ricos, problemas relacionados com a dependência continuada de uma fonte energética extra-europeia (o choque do petróleo), aumento do desequilíbrio das contas públicas e do desemprego, caminho lento e difícil para a coesão social, dúvidas 
quanto à aceitação geral de uma Constituição para toda a União. E o mais grave é que tudo isto era visto (e continua) em termos de diminuir o fosso económico entre a Europa e os EUA, e em alguns casos o Japão, e por vezes o temor dos desafios igualmente competitivos dos países emergentes como a China, a Índia e outros do sueste asiático. A data limite de 2010 já teve de ser prorrogada.

$\mathrm{Na}$ altura em que redigia esta longa Notícia sobre os dois primeiros volumes da Geografia de Portugal, no caderno Fórum Empresarial do jornal diário Público, dedicado a "Ciência e Tecnologia", de 17 de Abril de 2006, com o subtítulo de "Inovação. Futuro do País depende da I\&D”, a propósito do tão badalado Plano Tecnológico Nacional, apesar de um sopro de optimismo, reconhecia-se que Portugal surgia "continuamente na retaguarda dos índices de inovação, o que, evidentemente, penaliza o País no caminho da sua modernização e do seu próprio crescimento". Podendo ser acusado de ter retirado a frase do seu contexto, todavia, por mais voltas que sejam dadas, ela traduz uma realidade que nos preocupa a todos e que foi evidenciada por João Ferrão e Teresa Sá Marques. E dias depois, três documentos de análise da situação portuguesa, de origens diferentes, um do Banco de Portugal, outro da Organização para a Cooperação e Desenvolvimento Económico (OCDE) e outro do Fundo Monetário Internacional (FMI), coincidiam no diagnóstico negativo e no aconselhamento de medidas a tomar, entre as quais têm relevo, sobretudo na avaliação do segundo organismo, as de melhoria da "educação, da formação e da qualificação" do capital humano porquanto o País "tem um atraso considerável" em relação às médias europeias.

O segundo e o quinto capítulos do segundo volume, "Família e género" e "Desenvolvimento humano e coesão social", ficaram a dever-se a Isabel Margarida André, notável pelo didactismo das definições de tipos de situações caracterizantes das alterações da instituição familiar, sob a influência de factores internos e externos, da "reconfiguração das relações de género" e da coesão social, destacando transformações mais relevantes, vistas no plano global e no plano regional. Também aqui, a simples transcrição dos títulos e subtítulos acordará, certamente, a curiosidade e o desejo de informação dos leitores. Sob a rubrica de "Estruturas familiares em mudança: na encruzilhada entre autonomia individual, a centralidade dos afectos e a instabilidade dos laços", encontrará o leitor informações do maior interesse sobre sexualidade, conjugalidade e procriação - práticas dissociadas, relações do género mais equilibradas (dupla desinstitucionalização da conjugalidade; dissociação entre casamento e procriação; parentalidades desejadas e planeadas; uma geografia de síntese); e um percurso sinuoso pela igualdade de oportunidades e pela equidade social entre homens e mulheres (relações de género formatadas entre a repressão, a guerra colonial e as migrações; novos valores e novas práticas - o caminho da igualdade de oportunidades, vistas através da família, do emprego, nos campos da mobilidade, da disponibilidade e das qualificações, e ainda da cidadania), acreditando que serão enfraquecidas "as resistências mais conservadoras" e acelerados "os percursos da igualdade de oportunidades entre mulheres e homens".

Nas nove páginas e meia do quinto capítulo, explicada a razão da introdução do conceito de "desenvolvimento humano" pelas Nações Unidas (além das dimensões económica, as de bem-estar e desenvolvimento social e cultural), no seu Programa para o Desenvolvimento (PNUD), e não apenas de desenvolvimento ligado somente ao crescimento económico, foi feita "uma breve discussão das diversas dimensões analíticas do desenvolvimento na óptica da coesão social" através de duas perspectivas: evolução rápida nas últimas quatro décadas, e maiores vulnerabilidades do desenvolvimento 
humano (pobreza, défice de qualificações e info-exclusão, cidadania e participação), para chegar, muito ao gosto da autora (no segundo capítulo, por exemplo, os três tipos de transformações mais relevante, os três "países" de acordo com indicadores de conjugalidade e de fecundidade, os cinco grandes tipos de estruturas familiares), a cinco tipos do desenvolvimento humano pela utilização de seis dimensões de análise, sendo quatro de integração (familiar, social, escolar e no mercado de trabalho) e os outros de condições de alojamento e de rendimentos, com os respectivos indicadores, referidos a 2001.

O dinamismo da evolução populacional e as grandes transformações recentes (sobretudo após 1974) foram os temas escolhidos para o terceiro capítulo, sobre "Migrações", de Jorge Macaísta Malheiros. Aspecto relevante está no facto de Portugal, que fora um país de emigrantes, ter passado a ser um receptor de imigrantes, sendo analisados os factores de explicação das duas situações e a passagem de uma à outra. $\mathrm{Na}$ última parte do capítulo o autor também se referiu aos percursos e tendências dos não menos importantes movimentos migratórios internos. Mas as ligações com o exterior, num e noutro sentido, mereceram o maior desenvolvimento.

Interessante a "análise comparativa da geografia contemporânea do retorno" e a definição de três padrões distintos, o "francês", o "alemão" e o "americano", e dos critérios de caracterização das comunidades imigradas. Em "A afirmação de um país de imigração" foram sublinhadas diferentes fases, que assinalo resumidamente. A primeira dominada pelos africanos, marcada, desde meados dos anos 60, pela vinda maciça de caboverdeanos, numa altura de seca nas ilhas, fenómeno de causas climáticas sahelianas que se tem repetido ao longo do séculos, com as necessidade de mãode-obra em Portugal numa época de sangria de nacionais, sobretudo jovens, enviados para as guerras coloniais (Guiné, Angola e Moçambique), mas o grande boom esteve ligado, sem dúvida, com a descolonização dos antigos territórios ultramarinos e as lutas internas em Angola e Moçambique que trouxeram, a par dos inúmeros ditos "retornados", muitos outros. Nos anos 80 juntaram-se os asiáticos (sobretudo indianos, paquistaneses e chineses) e os sul-americanos (designadamente brasileiros); e nos finais do século passado, depois da queda do regime comunista e desmembrado o império soviético, foi a entrada maciça de gente do Leste da Europa, sobretudo ucranianos, dotados de níveis médios de instrução mais elevados do que os africanos, asiáticos ou sul-americanos.

Estas ondas imigratórias tiveram consequências sociais, económicas e até paisagísticas importantes. Por exemplo, Lisboa e a sua região mostram-se, à evidência, como um caleidoscópio racial, cultural e económico. Portugal foi-se tornando, cada vez mais, um país pluriétnico e de entrosagem de culturas. Nos seus espaços, sobretudo nos metropolitanos, coexistem indivíduos de várias origens, culturas e línguas; nalguns bairros "ghetizam-se" populações da mesma origem ou aparentadas, associadas a fenómenos de info-exclusão económica e social; na mesma área ou em áreas próximas podem estar a igreja católica, a ortodoxa, a sinagoga, a mesquita, o templo hindu ou budista, os centros de várias correntes religiosas de origens norte-americanas. Numa figura, sobre um mapa-mundo, o autor resumiu a participação do país em três sistemas migratórios distintos, caracterizados ainda em pequenas notas escritas: da antiga e consolidada estrutura emigratória euro-americana (no que toca à dispersão geográfica "seis países concentram cerca de $80 \%$ da diáspora portuguesa no exterior" - EUA, Canadá, Venezuela, Brasil, África do Sul e França); dos movimentos imigratórios ligados aos países lusófonos; e das vagas recentes e dinâmicas a partir de países da Europa oriental. 
Ao referir-se à importância e significado do sistema assente nos países lusófonos, e uma vez que em locais anteriores procurou dar imagens das transformações geográficas no País ligadas à distribuição dos seus imigrados, é pena que Jorge Malheiros não tivesse acrescentado umas linhas sobre a CPLP (a Comunidade de Países de Língua Portuguesa), organismo ainda por vezes balbuciante, mas que abarca países tão diferentes como o pequeno Portugal no extremo atlântico da Europa, progenitor colonial do Brasil subcontinental na América do Sul, de cinco países na África, dois pequenos arquipélagos e três continentais de tamanhos diferentes, um dos quais na margem do Índico, e ainda do insular e longínquo Timor entre a Indonésia e a Austrália. Diferem uns dos outros, mas todos eles defendem uma língua, a portuguesa. Com as suas colónias fixadas noutros países gerem esse sentimento de unidade dado pela utilização de língua comum, ainda que com as suas várias modulações: é o espaço vasto da lusofonia. Mutatis mutandis, podem ser aqui recordadas algumas afirmações de Serge Arnaud et al., em Les défis de la francophonie. Pour une mondialisation humaniste (2005): "de observador e de testemunha tímida", a Lusofonia, como a Fancofonia, "deve transformar-se em actor potente e exemplar na cena mundial"; formar "uma Comunidade verdadeira, actor maior da mundialização, afirmando o seu papel de espaço geocultural de solidariedade e de diálogo de culturas".

Para o sexto capítulo, como já referi anteriormente, Teresa Pinto Correia escreveu "Paisagem e identidade: da memória à pós-modernidade". São suas alíneas, uma introdução em que são citados diversos autores, incluindo Orlando Ribeiro; e outra de enquadramento conceptual, também com recurso a informações bibliográficas, para maiores demoras acerca de estudos originais, recentes e menos recentes, relativos a tipos e unidades de paisagens em Portugal continental (revalorizados os trabalhos de Orlando Ribeiro e o seu mapa das regiões geográficas, de 1945) e exemplos de identidade na gestão actual da paisagem portuguesa. Em conclusão a autora sublinhou a variedade de paisagens e de factores da sua sustentabilidade, e acrescentou a necessidade da "ponderação das várias questões que se põem em cada paisagem". Só depois deste capítulo aparece a lista bibliográfica dos que compõem a segunda parte (pp. 169173).

\section{À MANEIRA DE EPÍLOGO PARCIAL}

Repito o que já escrevi anteriormente: as minhas Notícias tinham de ser longas porque só assim podia relevar, jure optimo, o riquíssimo conteúdo científico e informativo desta Geografia de Portugal, original, diferente de outras, também notáveis, mas de épocas anteriores. Introduzi algumas notas resultantes da minha própria reflexão, que traduzem, tanto quanto possível, a leitura cuidada dos textos, a observação atenta de quadros estatísticos, de gráficos, da ilustração fotográfica e cartográfica.

O mesmo poderei um dia dizer dos volumes III - Actividades Económicas e Espaço Geográfico, 462 páginas, e IV - Planeamento e Ordenamento do Território, 471 páginas, ambos profusamente ilustrados, coordenados, respectivamente, por Carlos Alberto Medeiros, por Jorge Gaspar e José Manuel Simões, de que, por ora, dou apenas, de maneira corrida, os títulos das diferentes partes. No primeiro são: Actividades Rurais; A Floresta, na Memória e no Futuro do Espaço Rural; A Pesca; Energia; As Actividades Industriais; Os Serviços; O Comércio Retalhista: da Oferta de Bens às Experiências de Vida; Os Transportes; O Turismo e as Novas Dinâmicas Territoriais; e Envolvimento 
Económico Internacional: Comércio e Investimento. No segundo incluem-se Portugal: Território e Planeamento; Administração e Infra-estruturação do Território; Planeamento e Desenvolvimento; Ordenamento do Território; Expansão, Reabilitação e Renovação Urbana: Lições de Experiência; e Conclusões e Perspectivas.

Esta Geografia de Portugal é, sem dúvida, uma obra de referência importante, não só para os geógrafos mas também para todos os que queiram aprofundar os seus conhecimentos sobre temas e problemas do País, do passado e do presente, e pensar no que poderá vir a suceder em anos vindouros. Feita com rigor científico, por todo o lado transparecem as preocupações dos autores dos textos, universitários de méritos reconhecidos, com o uso de uma escrita acessível e equilibrada. 